\title{
Confounding influences of malnutrition and Plasmodium falciparum and Schistosoma haematobium infections on haematological parameters in school children in Muyuka, Cameroon
}

\author{
Irene Ule Ngole Sumbele ${ }^{1,2^{*}}$, Ofon Vitalis Otia ${ }^{1}$, Lorraine Francis ${ }^{3}$, Orelien Sylvain Mtopi Bopda ${ }^{1,4}$,
} Calvin Bisong Ebai ${ }^{1,5}$, Teh Rene Ning ${ }^{1}$, Helen Kuo Kuo Kimbi ${ }^{1,5}$ and Theresa Nkuo-Akenji ${ }^{6}$

\begin{abstract}
Background: School-aged children $(S A C)$ are a high-risk demographic group for infectious diseases and malnutrition. The objective of this study was to assess the burden and the effect of Plasmodium falciparum and schistosoma haematobium infections on the haematological indices in SAC and the confounding influence of malnutrition on the outcomes.

Methods: This cross-sectional study was conducted in SAC 4-14 years old living in Ikata, Bafia and Mile 14-Likoko in Muyuka, Cameroon. Anthropometric measures of malnutrition were obtained and blood samples collected were used for detection of malaria parasites by Giemsa-stained blood films using light microscopy and complete blood count analysis using an automated haematology analyser. Urine samples collected were used to detect micro haematuria with the aid of reagent strips and the eggs of S. haematobium by urine filtration technique. Multiple linear regression model was used to examine influence of independent variables on haematological parameters.

Results: Out of the 606 SAC examined, the prevalence of single infections with Plasmodium or S. haematobium and co-infection with both parasites was 16.2, 16.3 and 8.3\%, respectively. Overall, malaria parasite (MP), urogenital schistosomiasis, malnutrition, anaemia, haematuria, microcytosis and thrombocytopenia was prevalent in 24.4, 24.6, $25.9,74.4,12.2,45.4$ and $11.1 \%$ of SAC, respectively. A significant linear decline $(P=0.023)$ in prevalence of $P$. falciparum infection with the severity of stunting was observed. Factors that significantly influenced haematological parameters included haemoglobin: age, stunting and MP; haematocrit: age and MP; white blood cell count: age; red blood cell count; age and MP; lymphocyte counts: stunting; mean cell volume: age; mean cell haemoglobin: age and stunting; mean cell haemoglobin concentration: sex, stunting and red cell distribution width-coefficient of variation: sex, age and stunting.
\end{abstract}

\footnotetext{
* Correspondence: Sumbelei@yahoo.co.uk

'Department of Zoology and Animal Physiology, University of Buea, Buea,

Cameroon

${ }^{2}$ Department of Microbiology and Immunology, College of Veterinary

Medicine, Cornell University, Ithaca, New York, USA

Full list of author information is available at the end of the article
}

(c) The Author(s). 2021 Open Access This article is licensed under a Creative Commons Attribution 4.0 International License, which permits use, sharing, adaptation, distribution and reproduction in any medium or format, as long as you give appropriate credit to the original author(s) and the source, provide a link to the Creative Commons licence, and indicate if changes were made. The images or other third party material in this article are included in the article's Creative Commons licence, unless indicated otherwise in a credit line to the material. If material is not included in the article's Creative Commons licence and your intended use is not permitted by statutory regulation or exceeds the permitted use, you will need to obtain permission directly from the copyright holder. To view a copy of this licence, visit http://creativecommons.org/licenses/by/4.0/ The Creative Commons Public Domain Dedication waiver (http://creativecommons.org/publicdomain/zero/1.0/) applies to the data made available in this article, unless otherwise stated in a credit line to the data. 
Conclusions: Malnutrition, Plasmodium and S. haematobium infections are common while anaemia is a severe public health problem in Muyuka, Cameroon. The interaction between haematological parameters with malaria parasites as well as linear growth index was negative and other interactions indicate systemic inflammation. While findings provide contextual intervention targets to ensure the judicious use of the limited resources, there is need for regular monitoring and proper treatment to improve the health of the underserved population.

Keywords: Anaemia, Co-infection, Haematological parameter, Malnutrition, Plasmodium, School-aged children, Stunting, S. Haematobium, Cameroon

\section{Background}

Malaria caused by protozoan parasites such as Plasmodium falciparum and urogenital schistosomiasis (UGS) caused by the trematode helminth Schistosoma haematobium impose tremendous public health burdens in tropical and subtropical countries. Both diseases have been associated with poverty and factors such as low socioeconomic status, poor sanitation, limited access to safe water, poor education and poor awareness, which also play a key role in their transmission [1-3].

Beyond the pre-school years, school-aged children (SAC) are a high-risk demographic group for infectious diseases and malnutrition. Malaria whose symptoms and signs (anaemia, fever, headaches, vomiting, nausea, abdominal pain, inappetence, bitter mouth, dizziness, and weakness) may be more subtle in partially immune children, is increasingly an important challenge in SAC even though they have attracted relatively little attention as a group in need of special protection measures [4, 5]. Previous studies have underappreciated the burden amongst whom the prevalence of infection is habitually higher than that among children less than 5 years old and adults [6-8]. Following the scale-up of treated bed nets across the country between 2000 and 2015, a significant decrease in the overall prevalence of malaria cases from 41 to $24.3 \%$ was reported in Cameroon [9]. With the changing dynamics of malaria transmission and infection due to interventions, which include case management using artemisinin-based combination therapy (ACT) drugs and vector control through the large-scale distribution of long-lasting impregnated net (LLINs), monitoring the changes in morbidity in this age group is invaluable.

Like most neglected tropical diseases (NTD), schistosomiasis is a chronic and debilitating illness with the ability to affect child development and productivity. Children aged 5-17 years in developing countries are at highest risk of infection and are the most infected group $[10,11]$. Schistosomiasis is likely to cause anaemia, stunting and a reduced ability to learn although the effects are usually reversible with treatment [12]. In Cameroon, rural areas are the most affected with UGS. However recent report highlights the emergence of urban urogenital schistosomiasis in the Mount
Cameroon area in Tiko Health District, which can be attributed to the migration of individuals from the conflict hit areas of Kumba, Munyenge and Kotto-Barombi [13]. The prevalence of S. haematobium in the Mount Cameroon area ranges from 25.4-40.27\% although, the annual mass drug administration (MDA) campaigns control strategy in SAC has considerably reduced the egg-patent prevalence of the disease [14-17]. However, after several rounds of localized MDA campaigns and the fact that transmission dynamics and re-infection patterns post-treatment are complex [18], monitoring the variation of intensity of infection and associated morbidity is crucial in ascertaining the sustained impact of control measures or react to new outbreaks.

Since SAC are often under-represented in infectious diseases community-based cluster surveys, malaria and UGS burden in this group is poorly defined. Hence, the objective of this study was to assess the burden and the influence of infections with P. falciparum and S. haematobium on haematological parameters in SAC and the confounding influence of malnutrition on the outcomes in order to provide an insight on morbidities associated with co-infections in areas with ongoing interventions in place. The findings will provide contextual intervention targets in the community to ensure the judicious use of the limited resources in improving the health of the underserved population.

\section{Methods}

\section{Study area and participants}

The study was carried out in the schistosomiasis endemic foci of Ikata, Bafia and Mile 14-Likoko, which are three rural localities in the Muyuka Health District. The study sites have been described in detailed by Ebai et al. [19]. Environmental and socio-economic conditions in these areas favour the thriving of the vectors and the transmission of these parasites. A prevalence of malaria parasite (MP) of $35.5 \%$ and UGS of $34.3 \%$ was reported in the area in a study of a cross section of the population $[7,14]$. Intervention measures in the area include but are not limited to the free distribution of LLINs to pregnant women and children and the mass distribution of mebendazole by the Ministry of Public Health in Cameroon to SAC in schools. 
This study was conducted among SAC aged 4-14 years of both sexes whose parents consented to their participation in the study. As an inclusion criterion, only children who had resided for at least 3 months in the study area were enrolled in the study and their participation in the study was voluntary.

\section{Study design, sample size estimation and sampling}

This cross-sectional study was carried out between March to June 2015 to coincide with the malaria and schistosomiasis transmission season. This was a repeated cross-sectional study following intervention studies in the previous transmission season [7, 14]. The sample size of participants to be examined was determined using the formula $n=Z^{2} p q / d^{2}[20]$, where $n$ was the sample size required; $\mathrm{Z}$ was 1.96 , which is the standard normal deviate (for a 95\% confidence interval, CI); p was $35.3 \%$ or $34.3 \%$, the proportion of malaria parasite or UGS prevalence reported previously in the area [7, 14]; q was 1-p, the proportion of MP or UGS negative; and d was 0.05 , the acceptable error willing to be committed. The optimum sample size was estimated to be 349 $(359.5+346.3 / 2)$. To mitigate against possible loss of samples due to blood clotting and withdrawal from the study, the sample size was increased by $15 \%$ for a minimum of 401 SAC. With respect to sampling to obtain a representative minimum sample of 401 firstly, 8 primary schools from a list of schools from the three study sites of Likoko, Ikata and Bafia were selected randomly. Secondly, participants were selected at random by balloting from each class accounting for the numbers above the calculated sample size. Likoko village with the highest number of primary schools had the highest number of study participants followed by Ikata and Bafia.

\section{Implementation of study}

The inhabitants of Likoko, Ikata and Bafia were educated on the importance, benefits and protocol of the study in several reconnaissance visits made to the localities prior to the commencement of the study. Children who presented consent forms signed by parent / caregiver were enrolled into the study and information on both demography and factors that may be associated with malaria and UGS were obtained through an interview using a simple structured questionnaire. Clinical evaluation by the study nurse was carried out subsequently where weight, height and temperature were measured. The study involved the collection of venous blood and one urine sample for haematological analysis, and microscopic detection of S. haematobium eggs, respectively. Labelled blood and urine samples placed on ice blocks were transported to the University of Buea Malaria Research Laboratory for further analysis.

\section{Questionnaire administration and clinical evaluation}

A pre-tested questionnaire was administered to each participant with the aid of the teachers to obtain information on demography, hygienic practices, possible risk factors of Plasmodium and helminth infections as well as malnutrition and anaemia. The ages of participants were obtained from the school register.

The axillary temperature was measured using a digital thermometer and a participant with body temperature $\geq$ $37.5^{\circ} \mathrm{C}$ was considered febrile.

Height was measured to the nearest $0.1 \mathrm{~cm}$ using a graduated ruler of length $2 \mathrm{~m}$. Body mass was measured to the nearest $0.5 \mathrm{Kg}$ using a mechanical scale of capacity $120 \mathrm{Kg}$ (KINLEE ${ }^{\oplus}$ model BR9310), and upper arm circumference was measured to the nearest $0.1 \mathrm{~cm}$ using a graduated tape. These measurements were used to calculate an array of anthropometric indices used as proxies for malnutrition: weight-for-age (WA: under-weight); height-for-age (HA: stunting); weight-for height (WH: wasting). Anthropometric indices were computed as zscores based on the WHO growth reference curves using the WHO AnthroPlus for personal computers manual [21]. A child was identified as being malnourished if he or she scored $<-2$ in one of the anthropometric indices. A $\mathrm{z}$-score between $<-2$ and $\leq-3$ was considered as moderate wasting, moderate stunting or moderate underweight while $\mathrm{Z}$ scores of $<-3$ indicated severe wasting, severe stunting or severe underweight [22].

\section{Malaria parasite diagnosis and full blood count}

From each participant, approximately $2 \mathrm{ml}$ of venous blood was collected in ethylenediamine tetra-acetate tubes for malaria parasite detection and haematological analysis. Thick and thin blood films were prepared in situ. The thin blood films were fixed in absolute methanol and together with the thick blood films were Giemsa stained and examined microscopically following standard procedures [23]. Slides were considered positive when asexual forms and/or gametocytes of any Plasmodium species were observed on the blood film. All the slides were read twice by two independent microscopists. Malaria parasite per $\mu \mathrm{L}$ of blood was established by counting the number of parasites per 200 leukocytes and multiplying by the persons white blood cell (WBC) count. Parasitaemia was classified as low $(\leq 500$ parasite $/ \mu \mathrm{L}$ of blood), moderate (501-5000 parasites $/ \mu \mathrm{L}$ of blood) and high (> 5000 parasites/ $\mu \mathrm{L}$ of blood) [24].

A complete blood count analysis was done using a Beckman coulter counter (URIT 3300) which automatically gave values for red blood cell (RBC), WBC and platelet counts, haemoglobin (Hb), haematocrit (Hct), mean cell volume (MCV), mean cell haemoglobin $(\mathrm{MCH})$, mean cell haemoglobin concentration $(\mathrm{MCHC})$ and red cell distribution width-coefficient of variation 
(RDW-CV) following the manufacturer's instructions. The classification of anaemia ( $\mathrm{Hb}$ concentration below the WHO reference values for age or gender) and its severity was done in accordance with WHO standards (mild anaemia $=10-10.9 \mathrm{~g} / \mathrm{dL}$, moderate anaemia $=7-$ $9.9 \mathrm{~g} / \mathrm{dL}$ and severe anaemia $<7 \mathrm{~g} / \mathrm{dL}$ ) $[23,25]$.

\section{Urine analysis for haematuria and schistosome eggs}

Each study participant collected approximately $25 \mathrm{~mL}$ of midstream urine into a screw cap vials after a brisk exercise between 10 am and $2 \mathrm{pm}$. Gross haematuria was determined by visual observation while micro haematuria was determined with the aid of reagent strips (combistix) following the manufacturer's guide $\left(\mathrm{CYBOW}^{\mathrm{Tm}} 11 \mathrm{M}\right.$ a series of Health Mate Ref 0974). Eggs of S. haematobium were detected using the urine filtration technique. Following agitation, $10 \mathrm{~mL}$ of urine was drawn using a syringe and filtered through a polycarbonate membrane filter (STERLITECH corporation, USA). The filter membrane was examined microscopically for the presence of S. haematobium eggs as described by Cheesbrough [23]. S. haematobium egg density was expressed as the number of eggs in $10 \mathrm{~mL}$ urine $(\mathrm{e} / 10 \mathrm{~mL})$ and the intensity of infection was categorised as either light $(<50 \mathrm{e} / 10 \mathrm{~mL})$ or heavy infection $(\geq 50 \mathrm{e} / 10 \mathrm{~mL})[26,27]$.

\section{Data analysis}

Descriptive measures such as the mean and standard deviation (SD), geometric means, frequencies, and proportions were used to summarize data. Differences in proportions between populations were compared using Chi $\left(x^{2}\right)$ test. The attributable risk (AR\%) of anaemia caused by malaria, UGS and stunting was calculated accordingly [28]: $\left[\left(\mathrm{n}_{1} m_{0}-n_{0} m_{1}\right) / n\left(n_{0}+m_{0}\right)\right] \times 100$, where $\mathrm{n}_{0}=$ anaemic children without malaria/UGS/stunting and $\mathrm{n}_{1}=$ anaemic children with malaria/UGS/stunting, whereby $\mathrm{n}_{0}+\mathrm{n}_{1}=\mathrm{n}, \mathrm{m}_{0}=$ non anaemic children without malaria/UGS/stunting, and $\mathrm{m}_{1}=$ non anaemic children with malaria/UGS/stunting, whereby $\mathrm{m}_{0}+\mathrm{m}_{1}=\mathrm{m}$. Geometric means were computed for those positive only and the $\log$ transformed counts were used in the analysis. Geometric mean parasite density (GMPD) of P. falciparum and geometric mean egg count (GMEC) of $S$. haematobium by age, sex and nutritional status and severity were compared by the Student's t-test, and Mann Whitney $U$ test where appropriate and the mean haematological parameters were compared by analysis of variance (ANOVA). Potential confounders of haematological values to be entered into a multiple linear regression (MLR) model were identified after exploratory analysis. Any potential confounder with a moderate $(P<$ $0.2)$ relation with both the dependent variable and the confounder of interest was included in the later MLR models. The 95\% confidence interval (CI) was reported and $P$-values $<0.05$ were considered suggestive of statistical significance. All data was analysed using IBMStatistical Package for Social Science (SPSS) version 21 (IBM-SPSS Inc., Chicago, IL, USA).

\section{Ethical considerations}

The study protocol was reviewed and approved by the Institutional Ethical Review Board hosted by the Faculty of Health Sciences, University of Buea following administrative authorisation from the Regional Delegation of Public Health and Basic Education. The ethical approval reference for the study is 2014/243/UB/FHS/IRB. The study was conducted in accordance with the World Medical Association (WMA) principles as stated in the Declaration of Helsinki. The population was sensitized in their various communities at the beginning of the study. Written informed consent was obtained from all parents/caregivers whose child/children participated in the study after explaining the purpose and benefits of their participation. Participation was totally voluntary, and a participant could decide to halt their participation in the study at any time without any penalty. Participants who had malaria and or urogenital schistosomiasis were given first line treatment as recommended by the national treatment guideline policy for uncomplicated malaria and helminths.

\section{Results}

\section{Characteristics of participants}

The characteristics of the 606 SAC examined is presented in Table 1. The mean (SD) age of the study participant was 8.94 (2.1) years with no significant difference between sex and age. The majority (59.2\%) of the SAC were enrolled from the Likoko locality. The clinical profile of the participants revealed a prevalence of anaemia, malaria parasite, UGS, haematuria, microcytosis and thrombocytopenia of 74.4, $24.4,24.6,12.2,45.4$ and $11.1 \%$, respectively. While no significant difference in prevalence of malaria parasite was observed with sex and age, significantly higher prevalence of anaemia was observed in children 4-9 years old (78.5\%), UGS and haematuria in females $(28.6,14.9 \%)$ and thrombocytopenia in those 4-9 years old (13.4\%) than their respective contemporaries. The prevalence of microcytosis was significantly higher in males (50.7\%) and children 4-9 years (51.7\%). Likewise, the prevalence of malnutrition (25.9\%) and its forms such as underweight (6.6\%) and stunting (22.9\%) varied significantly with sex and age with a higher prevalence observed in males and children $10-14$ years as shown in Table 1. 
Table 1 Characteristics of study participants by sex and age

\begin{tabular}{|c|c|c|c|c|c|c|c|c|}
\hline \multirow{2}{*}{\multicolumn{2}{|c|}{ Parameter }} & \multicolumn{3}{|l|}{ Sex } & \multicolumn{2}{|c|}{ Age group in years } & \multirow[t]{2}{*}{ Overall } & \multirow{2}{*}{$\begin{array}{l}P \text { - } \\
\text { value }\end{array}$} \\
\hline & & Female & Male & $P$-value & $4-9$ & $10-14$ & & \\
\hline \multicolumn{2}{|l|}{$\%(\mathrm{~N})$} & $50.8(308)$ & $49.2(298)$ & & $59.1(358)$ & $40.9(248)$ & $100(606)$ & \\
\hline \multicolumn{2}{|c|}{ Mean age (SD) in years } & $8.97(2.0)$ & $8.91(2.3)$ & 0.724 & $7.50(1.4)$ & $11.0(1.1)$ & $8.94(2.1)$ & $<0.001$ \\
\hline \multicolumn{2}{|c|}{ Mean height (SD) in $\mathrm{cm}$} & $126.6(12.3)$ & $123.7(12.3)$ & 0.004 & $118.7(10.1)$ & $134.5(9.0)$ & $125.2(12.4)$ & $<0.001$ \\
\hline \multicolumn{2}{|c|}{ Mean weight (SD) in kg } & $28.2(7.0)$ & $27.6(9.3)$ & 0.431 & $24.4(4.7)$ & $33.1(9.3)$ & $27.9(8.2)$ & $<0.001$ \\
\hline \multirow[t]{4}{*}{ Site $\%(n)$} & Bafia & $18.2(56)$ & $14.4(43)$ & & $14.2(51)$ & $19.4(45)$ & $16.3(99)$ & \\
\hline & Ikata & $25.3(78)$ & $23.5(70)$ & 0.315 & $24.3(87)$ & $24.6(61)$ & $24.4(148)$ & 0.216 \\
\hline & Likoko & $56.5(174)$ & $62.1(185)$ & & $61.5(220)$ & $56.0(139)$ & $59.2(359)$ & \\
\hline & & & Clinical profi & & & & & \\
\hline \multicolumn{2}{|c|}{ Fever prevalence (n) } & $20.1(61)$ & $23.6(69)$ & 0.292 & $22.1(77)$ & $21.4(53)$ & $21.8(130)$ & 0.826 \\
\hline \multicolumn{2}{|c|}{ Anaemia prevalence (n) } & $74.0(228)$ & $74.8(223)$ & 0.820 & $78.5(281)$ & $68.5(170)$ & $74.4(451)$ & 0.006 \\
\hline \multicolumn{2}{|c|}{ Malaria parasite prevalence (n) } & $25.6(79)$ & $23.2(69)$ & 0.475 & $24.9(89)$ & $23.8(59)$ & $24.4(148)$ & 0.73 \\
\hline \multicolumn{2}{|c|}{ Asymptomatic malaria prevalence (n) } & $20.8(64)$ & $17.8(53)$ & 0.351 & $19.8(71)$ & $18.5(46)$ & $19.3(117)$ & 0.694 \\
\hline \multicolumn{2}{|c|}{ UGS prevalence (n) } & $28.6(88)$ & $20.5(61)$ & 0.021 & $23.5(84)$ & $26.2(65)$ & $24.6(149)$ & 0.440 \\
\hline \multicolumn{2}{|c|}{ Haematuria prevalence (n) } & $14.9(46)$ & $9.4(28)$ & 0.037 & $11.2(40)$ & $13.7(34)$ & $12.2(74)$ & 0.348 \\
\hline \multicolumn{2}{|c|}{ aUnderweight prevalence (n) } & $4.3(10)$ & $8.9(20)$ & 0.044 & $5.3(19)$ & $11.0(11)$ & $6.6(30)$ & 0.042 \\
\hline \multicolumn{2}{|c|}{ Stunting prevalence $(n)$} & $16.9(52)$ & $29.2(87)$ & $<0.001$ & $17.9(64)$ & $30.2(75)$ & $22.9(139)$ & $<0.001$ \\
\hline \multicolumn{2}{|c|}{ bWasting prevalence (n) } & $9.1(1)$ & $4.5(1)$ & 0.606 & $6.1(2)$ & & $6.1(2)$ & \\
\hline \multicolumn{2}{|c|}{ Malnutrition prevalence (n) } & $19.2(59)$ & $32.9(98)$ & $<0.001$ & $21.2(76)$ & $32.7(81)$ & $25.9(157)$ & 0.002 \\
\hline \multicolumn{2}{|c|}{ Leucopenia prevalence (n) } & $1.9(6)$ & $2.0(6)$ & 0.954 & $2.0(7)$ & $2.0(5)$ & $2.0(12)$ & 0.958 \\
\hline \multicolumn{2}{|c|}{ Microcytosis prevalence (n) } & $40.3(124)$ & $50.7(298)$ & 0.010 & $51.7(185)$ & $36.3(90)$ & $45.4(275)$ & $<0.001$ \\
\hline \multicolumn{2}{|c|}{ Thrombocytopaenia prevalence (n) } & $11.0(34)$ & $11.1(33)$ & 0.989 & $13.4(48)$ & $7.7(19)$ & $11.1(67)$ & 0.027 \\
\hline
\end{tabular}

anderweight was evaluated for 458 SAC

${ }^{b}$ Wasting was evaluated for 33 SAC

$P$-values in bold are statistically significant.

\section{Prevalence of single and co-infection}

The prevalence of single infection with $P$. falciparum or S. haematobium and co-infection with both parasites was $16.2,16.3$ and $8.3 \%$, respectively, with no significant variation with sex and age. Significantly higher $(P<$ $0.001 ; P<0.001$ and $P=0.001)$ prevalence of single infection with S. haematobium (25.9\%) and co-infection with P. falciparum and S. haematobium (13.4\%) were observed in SAC from the Likoko locality while single $P$. falciparum infection was observed in Ikata (20.9\%), respectively. The higher prevalence observed in the anaemics was not statistically significant when compared with their counterparts as shown in Table 2. The prevalence of $P$. falciparum and $S$. haematobium was lower in children who presented with fever contrary to the significantly higher $(P=0.008)$ prevalence of co-infection observed in those with fever (13.8\%). With regard to malnutrition and its forms, the prevalence of $S$. haematobium and co-infection was comparable among the different groups unlike that of $P$. falciparum. The prevalence of $P$. falciparum was significantly lower $(P=$ $0.018, P=0.006)$ in those malnourished $(10.2 \%)$ or the stunted (8.6\%) than those normal, respectively (Table 2).
Observation from the study demonstrated a significant linear decline $\left(\chi^{2}=7.516, P=0.023\right)$ in prevalence of $P$. falciparum infection with the severity of stunting with those normal having the highest prevalence (18.4\%) while those with severe stunting had the least (6.5\%). No significant trend in the prevalence of S. haematobium and coinfection was observed with the severity of stunting even though the prevalence was lowest in those with severe stunting (12.9 and 3.2\%, respectively) as revealed in Fig. 1.

\section{Malnutrition severity and infection intensity}

The prevalence of moderate and severe stunting was 17.7 and 5.1\%, respectively. Males and children 10-14 years old had significantly higher $\left(X^{2}=14.105, P=0.001\right.$; $\left.X^{2}=11.986, P=0.002\right)$ prevalence of moderate and severe stunting, respectively, as shown in Fig. 2.

Plasmodium falciparum parasitaemia ranged from 71 to 33,250 parasites $/ \mu \mathrm{L}$ of blood while $S$. haematobium eggs $/ 10 \mathrm{~mL}$ of urine ranged from 1 to 494 . Although males, children 4-9 years, the malnourished and those with severe stunting had a higher P. falciparum GMPD/ $\mu \mathrm{L}$ of blood the differences were not statistically significant. A similar pattern in the distribution of $S$. 
Table 2 Prevalence of single infection with P. falciparum or S. haematobium and co-infections by demographic and clinical status

\begin{tabular}{|c|c|c|c|c|c|c|c|c|}
\hline \multirow[t]{2}{*}{ Parameter } & \multirow[t]{2}{*}{ Category } & \multirow[t]{2}{*}{$\mathbf{N}$} & \multicolumn{2}{|c|}{ Single $P$. falciparum infection } & \multicolumn{2}{|c|}{ Single S. haematobium infection } & \multicolumn{2}{|l|}{ Co-infection } \\
\hline & & & Prevalence (n) & $P$-value & Prevalence (n) & $P$-value & Prevalence (n) & $P$-value \\
\hline All & & 606 & $16.2(98)$ & & $16.3(99)$ & & $8.3(50)$ & \\
\hline \multirow[t]{2}{*}{ Sex } & Female & 308 & $15.3(47)$ & 0.535 & $18.2(56)$ & 0.212 & $10.4(32)$ & 0.052 \\
\hline & Male & 298 & $17.1(51)$ & & $14.4(43)$ & & $6.0(18)$ & \\
\hline \multirow[t]{2}{*}{ Age in years } & $4-9$ & 358 & $16.8(60)$ & 0.637 & $15.4(55)$ & 0.436 & $8.1(29)$ & 0.872 \\
\hline & $10-14$ & 248 & $15.3(38)$ & & $17.7(44)$ & & $8.5(21)$ & \\
\hline \multirow[t]{3}{*}{ Site } & Bafia & 99 & $4.0(4)$ & & $3.0(3)$ & & $0.0(0)$ & \\
\hline & Ikata & 148 & $20.9(31)$ & 0.001 & $2.0(3)$ & $<0.001$ & $1.492)$ & $<0.001$ \\
\hline & Likoko & 359 & $17.5(63)$ & & $25.9(93)$ & & $13.4(48)$ & \\
\hline \multirow[t]{2}{*}{ Anaemia status } & Anaemic & 451 & $17.3(78)$ & 0.200 & $17.7(80)$ & 0.111 & $9.1(41)$ & 0.200 \\
\hline & Normal & 155 & $12.9(20)$ & & 12.3 (19) & & $5.8(9)$ & \\
\hline \multirow[t]{2}{*}{ Fever status } & Fever & 130 & $10.8(14)$ & 0.054 & $15.4(20)$ & 0.756 & $13.8(18)$ & 0.008 \\
\hline & Normal & 466 & $17.8(83)$ & & $16.5(77)$ & & $6.7(31)$ & \\
\hline \multirow[t]{2}{*}{ Stunting } & Stunted & 139 & $8.6(12)$ & 0.006 & $16.5(23)$ & 0.939 & $7.2(10)$ & 0.606 \\
\hline & Normal & 467 & $18.4(86)$ & & $16.3(76)$ & & $8.6(40)$ & \\
\hline \multirow[t]{2}{*}{ Underweight } & Underweight & 30 & $20.0(6)$ & 0.731 & $16.7(5)$ & 0.937 & $6.7(2)$ & 0.835 \\
\hline & Normal & 428 & $17.5(75)$ & & $16.1(69)$ & & $7.7(33)$ & \\
\hline \multirow[t]{2}{*}{ Malnutrition } & Malnourished & 157 & $10.2(16)$ & 0.018 & $17.2(27)$ & 0.735 & $7.0(11)$ & 0.510 \\
\hline & Normal & 449 & $18.3(82)$ & & $16.0(72)$ & & 8.7 (39) & \\
\hline
\end{tabular}

$P$ - values in bold are statistically significant.

haematobium GMEC was observed except for sex with females having a higher GMEC (26 eggs/10 $\mathrm{mL}$ of urine) than males (20 eggs $/ 10 \mathrm{~mL}$ of urine) as shown in Table 3.

Of the 148 SAC infected with $P$. falciparum, the majority $(n=74,50 \%)$ had low parasite density. As shown in Fig. 3 (a), the prevalence of low, moderate and high $P$. falciparum density was $12.2,10.6$ and $1.7 \%$, respectively and this was lower in malnourished than well-nourished children. In addition, the prevalence of low and moderate $P$. falciparum density decreased with the severity of stunting. With respect to $S$. haematobium, the prevalence of low and high egg density was respectively, 16.3 and $8.3 \%$ and, a comparison with the nutritional status

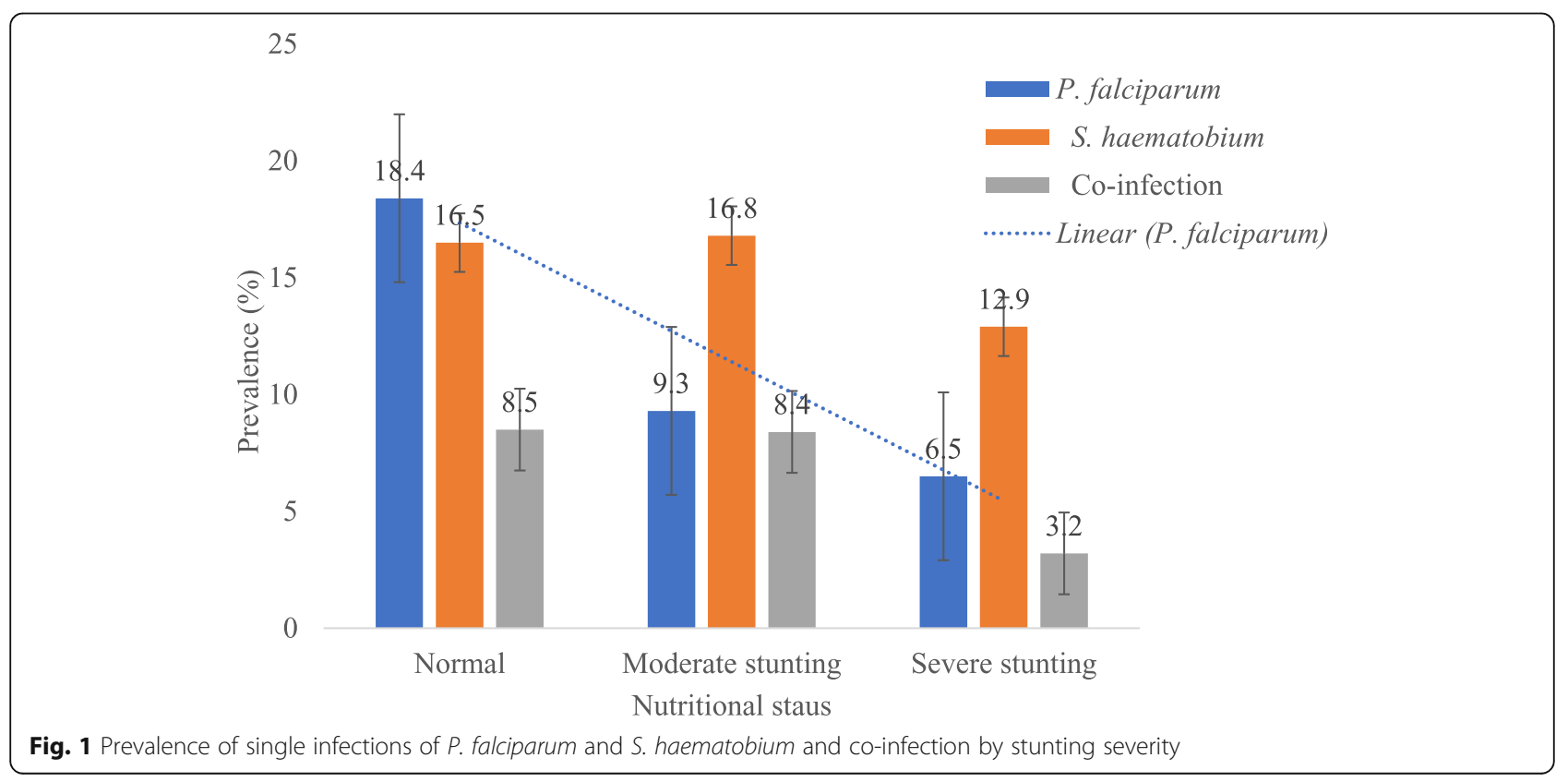




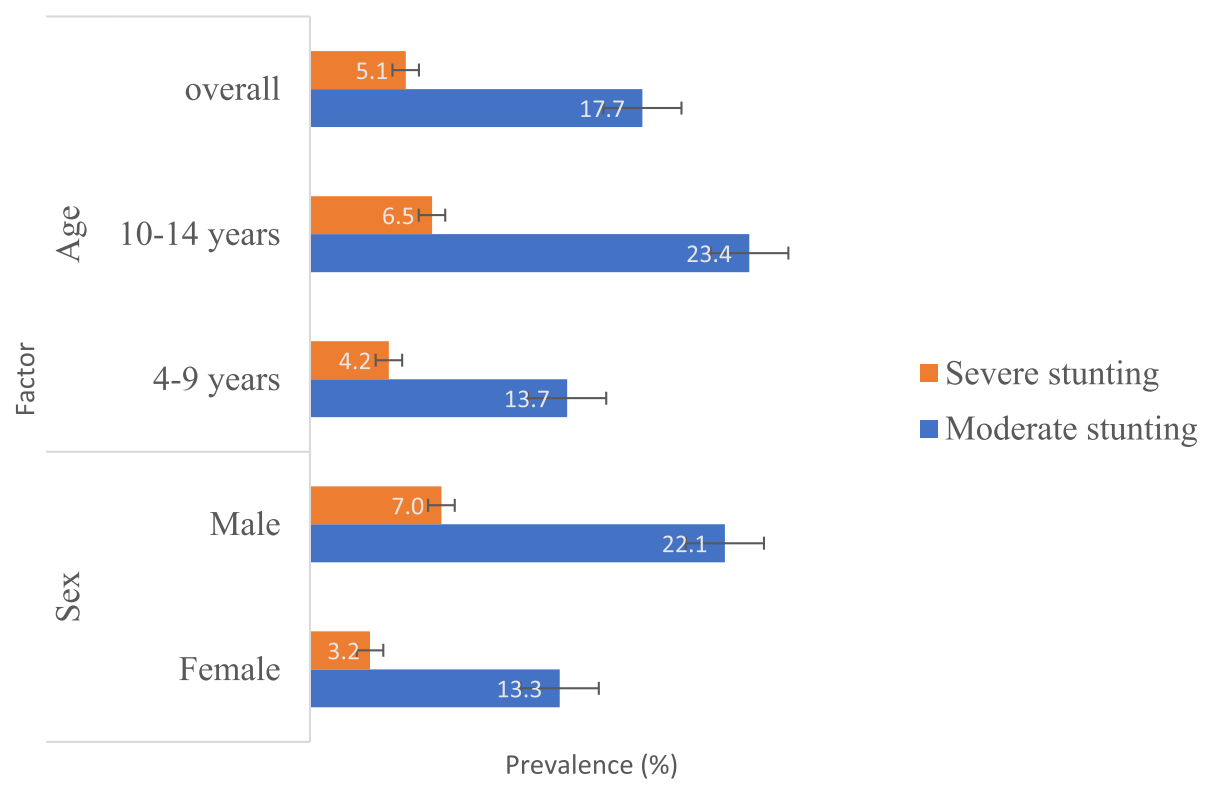

Fig. 2 Moderate and severe stunting prevalence by sex and age

showed no significant differences with the severity of stunting (Fig. 3 (b)).

\section{Effect on haematological parameters}

Anaemia was common in the study population (74.4\%) even in SAC negative for both infections (70.2\%). The prevalence of anaemia was significantly higher $\left(x^{2}=\right.$ $8.375, P=0.039)$ in children with co-infection $(82.0 \%)$ when compared with those with single infection and those negative for both infections. Mild, moderate and severe anaemia was prevalent in $17.3,54.8$ and $2.1 \%$ of the population, respectively. Although no significant difference $\left(X^{2}=10.765, P=0.292\right)$ in the severity of anaemia was observed, moderate anaemia was most common in children with co-infection (64\%) when compared with their counterparts as shown in Fig. 4. The population attributable risk of anaemia due to the malaria parasite, urogenital schistosomiasis, co-infection with both parasites and stunting in the study population was 2.6, 3.0, 0.9 and $2.8 \%$, respectively.

The mean Hct, WBC, lymphocyte and platelet counts, $\mathrm{MCV}, \mathrm{MCH}, \mathrm{MCHC}$ and $\mathrm{RDW}-\mathrm{CV}$ were comparable amongst those infected with P. falciparum, S. haematobium, and co-infection and those negative. Post hoc comparisons revealed a significantly lower $(P=0.028$, $P=0.035)$ mean $\mathrm{Hb}(10.5(1.2) \mathrm{g} / \mathrm{dL})$ concentration and mean RBC $\left(4.1(4.4) \times 10^{12} / \mathrm{L}\right)$ counts in children infected with $P$. falciparum when compared with those negative, respectively (Table 4).

A multiple linear regression analysis involving the 606 participants, with the different haematological variables as the dependent variable and sex, age, HAZ (stunting

Table 3 P. falciparum GMPD and S. haematobium GMEC by sex, age nutritional status and stunting severity

\begin{tabular}{|c|c|c|c|c|c|c|c|}
\hline \multirow[t]{2}{*}{ Parameter } & \multirow[t]{2}{*}{ Characteristics } & \multicolumn{3}{|c|}{ P. falciparum $/ \mu \mathrm{L}$ of blood } & \multicolumn{3}{|c|}{ S. haematobium $/ 10 \mathrm{~mL}$ of urine } \\
\hline & & GMPD (n) & Range & $P$ value & GMEC (n) & Range & $P$ value \\
\hline Overall & & $643(148)$ & $71-33,250$ & & $24(50)$ & $1-494$ & \\
\hline \multirow[t]{2}{*}{ Sex } & Female & $564(79)$ & $71-12,721$ & 0.156 & $26(32)$ & $1-494$ & $0.284^{*}$ \\
\hline & Male & 747 (69) & $140-33,250$ & & $20(18)$ & $1-280$ & \\
\hline \multirow[t]{2}{*}{ Age in years } & $4-9$ & $726(89)$ & $110-33,250$ & 0.129 & $25(29)$ & $1-494$ & $0.472^{*}$ \\
\hline & $10-14$ & $535(59)$ & $71-20,600$ & & $22(21)$ & $2-250$ & \\
\hline \multirow[t]{2}{*}{ Nutritional status } & Normal & $642(126)$ & $71-33,250$ & $0.785^{*}$ & $23(40)$ & $1-494$ & $0.701^{*}$ \\
\hline & Malnourished & $675(27)$ & $168-11,700$ & & $29(11)$ & $1-250$ & \\
\hline \multirow[t]{2}{*}{ Stunting Severity } & Moderate & $641(19)$ & $168-4230$ & $0.651^{*}$ & $24(9)$ & $1-250$ & $0.220^{*}$ \\
\hline & Severe & $674(3)$ & $270-3603$ & & $48(1)$ & 48 & \\
\hline
\end{tabular}

$P$ values obtained by t-test

*P value obtained by Mann Whitney U-test 


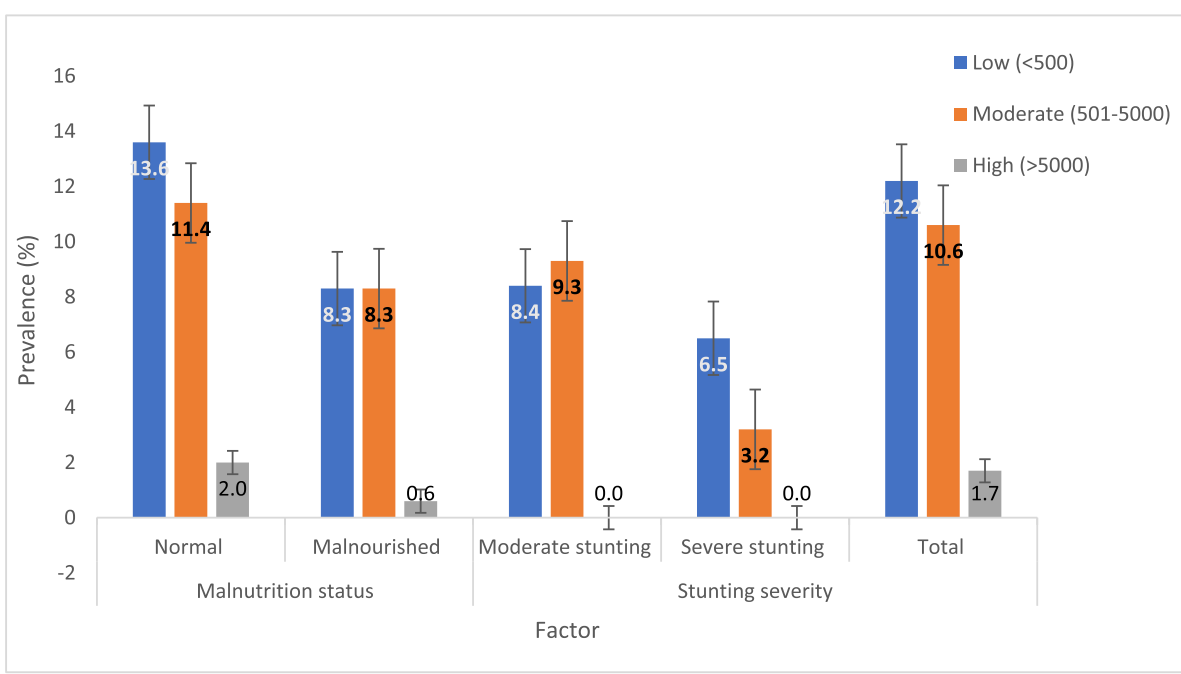

(a)

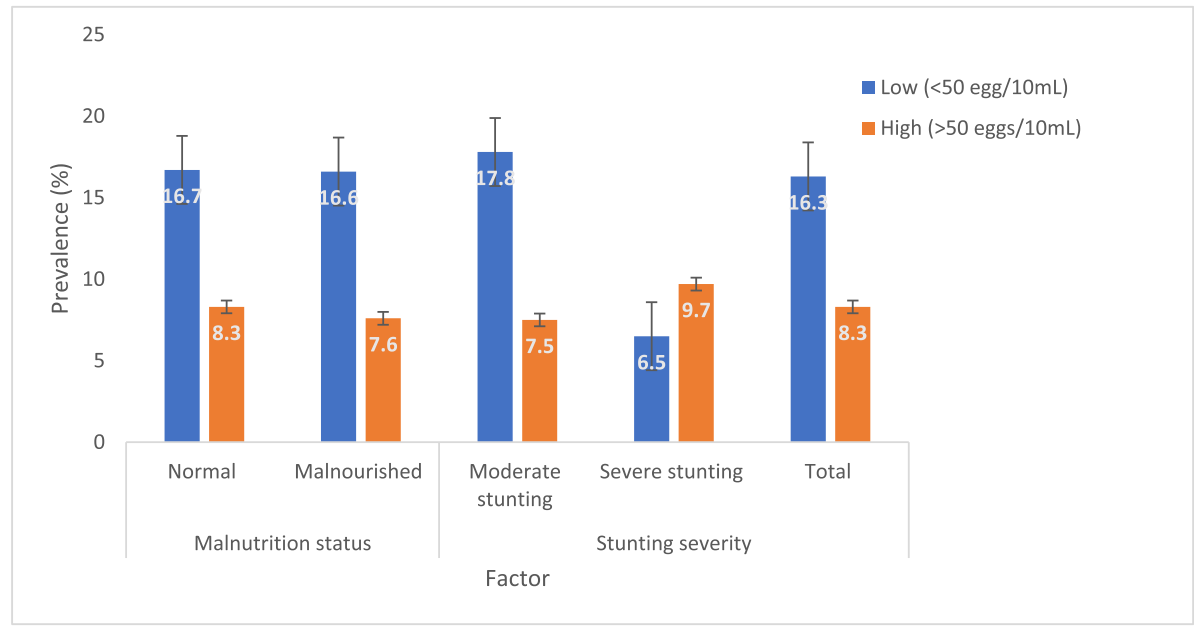

(b)

Fig. 3 P. falciparum (a) and S. haematobium (b) parasite density category prevalence by malnutrition status and severity of stunting

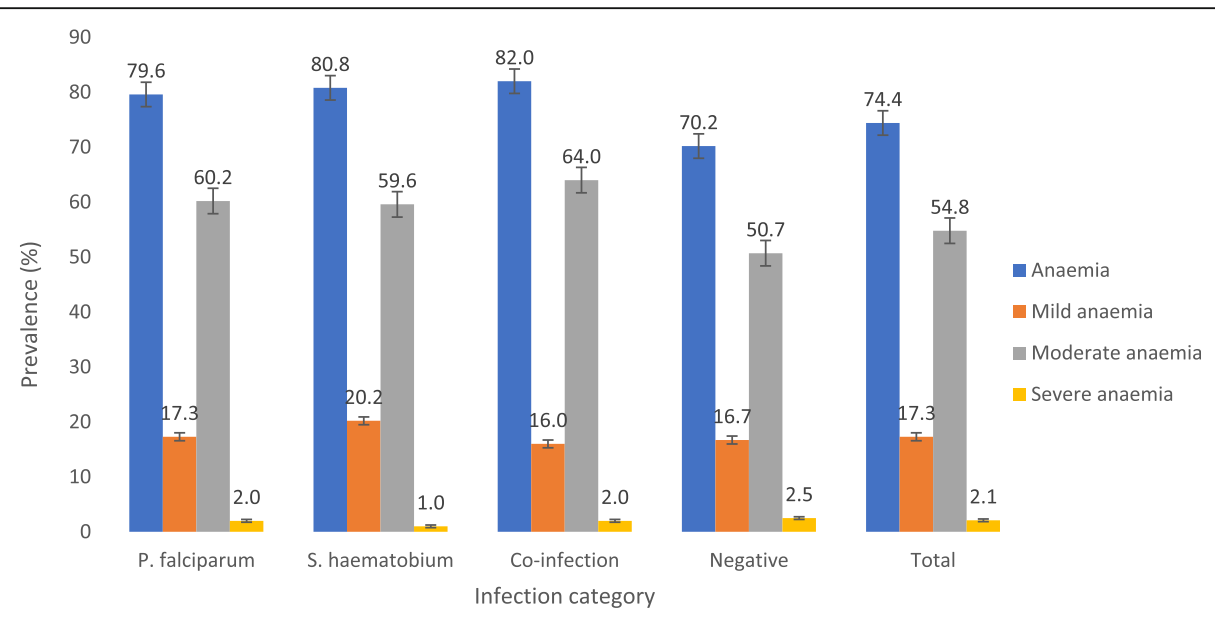

Fig. 4 Prevalence of anaemia and its severity by infection category 
Table 4 Mean (SD) haematological parameter as affected by infection category

\begin{tabular}{|c|c|c|c|c|c|c|}
\hline Parameter & P. falciparum & S. haematobium & Co-infection & Negative & Overall & $P$-value \\
\hline N & 98 & 99 & 50 & 359 & 606 & \\
\hline $\mathrm{Hb}$ in $\mathrm{g} / \mathrm{dL}$ & $10.5(1.2)^{\mathbf{a}}$ & $10.5(1.4)$ & $10.5(1.3)$ & $10.8(1.4)^{\mathbf{b}}$ & $10.7(1.4)$ & 0.059 \\
\hline Hct in \% & $30.0(3.5)$ & $30.3(4.0)$ & $30.2(3.7)$ & $30.9(3.9)$ & $30.6(3.9)$ & 0.157 \\
\hline $\mathrm{WBC} \times 10^{9} / \mathrm{L}$ & $9.5(4.9)$ & $9.3(2.7)$ & $9.3(3.0)$ & $9.9(5.6)$ & $9.6(5.0)$ & 0.621 \\
\hline $\mathrm{RBC} \times 10^{12} / \mathrm{L}$ & $4.1(4.4)^{\mathbf{a}}$ & $4.2(5.0)$ & $4.1(4.7)$ & $4.2(5.2)^{\mathbf{b}}$ & $4.2(5.0)$ & 0.135 \\
\hline Lymphocyte $\times 10^{9} \mathrm{~L}$ & $4.2(3.5)$ & $3.8(1.7)$ & $3.9(2.1)$ & $4.3(2.8)$ & $4.2(2.7)$ & 0.451 \\
\hline$M C V$ in $\mathrm{fL}$ & $73.4(6.0)$ & $73.2(6.7)$ & $73.1(6.1)$ & $73.4(6.1)$ & $73.3(6.2)$ & 0.984 \\
\hline $\mathrm{MCH}$ in pg & $25.5(2.2)$ & $25.3(2.3)$ & $25.4(2.4)$ & $25.5(2.2)$ & $25.5(2.2)$ & 0.808 \\
\hline$M C H C$ in $\mathrm{g} / \mathrm{L}$ & $34.8(1.8)$ & $34.7(1.8)$ & $34.8(2.4)$ & $35.0(2.1)$ & $34.9(2.0)$ & 0.724 \\
\hline Platelet $\times 10^{9} \mathrm{~L}$ & $276.2(111.9)$ & $279.0(975.0)$ & $253.5(118.7)$ & $280.9(113.7)$ & $277.6(111.3)$ & 0.442 \\
\hline RDW-CV\% & $12.5(1.3)$ & $12.7(1.4)$ & $12.4(1.2)$ & $12.5(1.4)$ & $12.5(1.3)$ & 0.514 \\
\hline
\end{tabular}

a, b Means with dissimilar superscript are significantly different

$P$ values obtained by ANOVA

index), MP status, UGS status and co infection as independent variables, revealed that co-infection did not significantly influence any haematological parameter (Additional file 1). Factors of significant influence on haematological parameters included $\mathrm{Hb}$ : age $(P<0.001)$, stunting $(P=0.004)$ and MP status $(P=0.013)$; Hct: age $(P<0.001)$ and MP status $(P=0.038)$; WBC: age $(P=$ $0.034)$; RBC: age $(P=0.001)$ and MP status $(P=0.034)$; lymphocyte counts: stunting $(P=0.015)$; $\mathrm{MCV}$ : age $(P<$ 0.001); $\mathrm{MCH}$ : age $(P<0.001)$ and stunting $(P=0.001)$; MCHC: sex $(P=0.046)$ and stunting $(P=0.004)$ and RDW-CV: sex $(P<0.001)$, age $(P=0.001)$ and stunting $(P=0.023)$ as shown in Additional file 1.

\section{Discussion}

Studies in the Mount Cameroon area have demonstrated the significant contributions of co-infection of Plasmodium and S. haematobium to the burden of anaemia in pregnant women [29] and the persistent transmission of schistosomiasis despite MDA and the burden of schistosomiasis in SAC [15]. In the present study we assessed the burden and influence of these infections on haematological indices in SAC and the confounding influence of malnutrition on the outcomes to provide some insight on the morbidities associated with co-infections in areas of ongoing intervention strategies.

Findings from the study revealed similar prevalence of both Plasmodium and S. haematobium with most infections being single, light and asymptomatic. A drop in prevalence was observed when compared with findings of studies carried out in the general population in the same area a year earlier [7, 14]. However, in schistosomiasis endemic areas, the outcome of infection with Plasmodium is of growing concern. The prevalence of Plasmodium (24.4\%) is lower than the $33.9 \%$ observed in a simultaneous study in SAC in non-schistosomiasis endemic area within the same Muyuka Health District [30]. These findings are, however, comparable with a 26.8 and $27.4 \%$ prevalence observed in similar populations in schistosomiasis endemic areas in the West Region of Cameroon [31] and North-western Tanzania, respectively [32]. While the decrease in the prevalence of infection in this cohort of children may be attributed to LLINs use and its community benefit, although SAC have a propensity to use LLINs less frequently, its use remains an effective method of malaria control $[4,7]$. Nonetheless, the interactions in epidemiology in schistosomiasis-endemic foci resulting in lower prevalence of Plasmodium infection when compared with non-endemic foci warrants further investigation.

Observations from the study revealed no significant differences in the prevalence of both Plasmodium and $S$. haematobium with age. On the other hand, UGS was more common in females with haematuria being a common manifestation consistent with other studies [33, 34]. This higher prevalence in females is consistent with observations made by Noriodea et al. [35] in Nigeria but contrasts those of Mewabo et al. [34] and Njunda et al. [36] in Cameroon and Abdulkareem et al. [37] in Nigeria. Although a higher prevalence of UGS in females may be attributed to their higher frequency of contact with infested water, for peri domestic activities, it is worth noting that limited access to safe water and sanitation conditions are implicated in the transmission of both Plasmodium and S. haematobium infections [2, 3].

The prevalence of Plasmodium and S. haematobium co-infection in SAC (8.3\%) is like that reported in Gabon [38], higher in Ghana [39] and lower when compared with some areas in Nigeria [40]. Ikata, Bafia and Mile 14-Likoko in Muyuka, Cameroon are S. haematobium endemic areas due to the presence of an efficient Bulinus snail vector and the use of untreated waterways for 
domestic, farming and recreational use. Risk of co- infection with Plasmodium in these areas is also high as these areas are part of the holoendemic stratum with high and perennial malaria parasite transmission [41]. Furthermore, environmental variants within the different localities maybe of significance accounting for the disproportionate distribution of infections in the localities with most of the co-infections observed in the Likoko locality.

Malnutrition prevalence, underweight and stunting varied significantly with sex and age with significantly higher occurrence of moderate and severe stunting in males and children 10-14 years. The prevalence of stunting is similar to that observed in SAC in Ghana [42], but higher than that observed in Northern Senegal [43] and in urban Cameroon [44]. The preponderance of linear growth retardation known as stunting in males has been well reported in Sub-Saharan Africa [45, 46]. Of note is the lower prevalence of Plasmodium infection and higher GMPD/ $\mu \mathrm{L}$ of blood in those malnourished or stunted with significant linear decline in infections with the severity of stunting. Similarly, the lowest prevalence of S. haematobium and co-infections and higher GMEC was observed in those with severe stunting. Despite the previous work by Olney et al. [47], which reported higher malaria parasite densities in children with lower height for age indices, Gari et al. [48] reported malaria as a risk factor for stunting although stunting was not associated with subsequent malaria illness. Stunting has been highlighted as a predictor of $S$. haematobium infection [42]. Whilst it is more likely that the severity of stunted malnutrition may have a negative influence on parasite density since both infections are transitory and severe stunting is chronic and prolonged nutritional inadequacies are required for it to manifest.

The hallmarks of $P$. falciparum infection include haematological alterations of which anaemia is the most common $[49,50]$ unlike in infections with $S$. haematobium and co-infections. The perpetual presence of anaemia in apparently healthy SAC negative for both infections with significantly higher occurrence in children 4-9 years old and those with coinfections necessitates caveat in attributing the causality of anaemia to these factors. Although the high prevalence of anaemia in those 4-9 years old could be linked to the high parasite densities of both P. falciparum and S. haematobium and microcytosis observed, the attributable risk of anaemia associated with these infections in the population remains low. Notwithstanding, findings from the multivariate analysis asserts a negative interaction between haemoglobin level with malaria parasites and $S$. haematobium as well as the association between haemoglobin and linear growth index.
While anaemia is one of the markers of morbidity associated with schistosomiasis even though it may be masked by anaemia resulting from malaria [51], the prevalence of anaemia in children co-infected with $P$. falciparum and $S$. haematobium was very high. This prevalence is similar with those in children in Ethiopia [52] with moderate anaemia being the most common form. Although the aetiology of anaemia is multifactorial, both infections may contribute to anaemia separately or through an interaction effect [51]. Nevertheless, the mechanism of malaria mediated anaemia has been well explained $[53,54]$ while anaemia by urogenital schistosomiasis may arise due to chronic blood loss as the egg penetrates the walls of the urinary tract, extra corporal loss of iron, autoimmune haemolysis and inflammation [55].

Findings from the study revealed that the mean Hct, WBC, lymphocyte and platelet counts, MCV, $\mathrm{MCH}$, $\mathrm{MCHC}$ and RDW-CV were comparable amongst those infected with $P$. falciparum or S. haematobium or coinfection and those not infected. Infections with P. falciparum however, significantly lowered the $\mathrm{Hb}$ concentration and mean RBC counts. This effect is further bolstered by the significant association of $P$. falciparum with red cell indices including $\mathrm{Hb}, \mathrm{RBC}$ and Hct in the multiple regression analysis. In line with findings by Kotepui et al. $[50,56]$, the negative association of $P$. falciparum infection with these red cell indices is not atypical and may be related to the enhanced destruction of infected and uninfected erythrocytes combined with decreased erythrocyte production leading to malaria related anaemia $[57,58]$.

Observations from the study highlighted age as a significant factor in most of the haematological parameters evaluated while sex was found to be associated with $\mathrm{MCHC}$ and RDW-CV. Since haematological parameters are interrelated with each other as well as with sex and age, of significance is the intricate positive interaction between the anthropometric malnutrition proxies of height-for-age and haematological parameters including haemoglobin, lymphocyte, $\mathrm{MCH}, \mathrm{MCHC}$ and $\mathrm{RDW}-\mathrm{CV}$. As noted in previous studies $[59,60]$, the positive association suggests it is likely that the children suffer from chronic malnutrition (stunting) in addition to anaemia as well as systemic inflammation demonstrated by the relationship with lymphocytes and RDW-CV, an integrative measure of the pathological process. While a decrease in lymphocytes is implicated in infection with malaria parasite and anaemia, the biological function of different cell types including $B$ lymphocytes has been reported to decrease during nutritional deficiencies [50, 61-63]. Nonetheless, the comparability of stunting to the population attributable risk of anaemia due to malaria and urogenital schistosomiasis demonstrates the ability to which stunting can exacerbate anaemia observed in the children. 
Other haematological abnormalities of significance observed in the study population included thrombocytopenia, and microcytosis which were higher in SAC 4-9 years old. Furthermore, a higher occurrence of microcytosis was observed in males than females. Thrombocytopenia is commonly found in individuals living in areas endemic for Schistosoma mansoni while, microcytosis and thrombocytopenia is common in individuals with malaria [64-67]. Its association in individuals with S. haematobium is, however, uncertain. Although the context of interpretation is limited to the few cases of thrombocytopenia observed, findings from the study demonstrated no statistically significant association between platelet counts and parasite densities. It is worthy to note that children in the 4-9 years old age group had the highest parasite densities of both Plasmodium and S. haematobium. On the other hand, the high prevalence of microcytosis in the population may be attributed to the high prevalence of anaemia observed which is partly accounted for by the presence of the parasitic infections and chronic nutritional deficiencies.

The findings of the study should be viewed in the context of the limitations of the cross-sectional nature of the design which did not provide the changes in the burden and morbidities following control measures that could have been captured in a longitudinal study. Hence, there is a need for further investigations to ascertain the causal relationship between enhanced control interventions and changes in demographic as well as clinical characteristics and burden in this at-risk group to formulate more appropriate public health interventions.

\section{Conclusions}

Plasmodium falciparum and S. haematobium infections are of public health concern while, malnutrition, microcytosis and thrombocytopenia are common, and anaemia is a severe public health problem in Muyuka, Cameroon. The interaction between haematological parameters with malaria parasites as well as linear growth index was negative even though the attributable risk of anaemia associated with these conditions remains low in the population. Other positive interactions between the linear growth index and haematological parameters indicate the occurrence of chronic malnutrition in addition to anaemia as well systemic inflammation. While findings provide contextual intervention targets to ensure the judicious use of the limited resources there is need for regular monitoring and proper treatment to improve the health of the underserved population.

\section{Abbreviations}

ACT: Artemisinin combination therapy; Cl: Confidence interval;

GMEC: Geometric mean egg count; GMPD: Geometric mean parasite density; Hct: Haematocrit; Hb: Haemoglobin; HA: Height-for-age; LLINs: Long-lasting insecticidal nets; MDA: Mass drug administration; MP: Malaria parasite;
MCH: Mean cell haemoglobin; MCHC: Mean cell haemoglobin concentration; MCV: Mean cell volume; MLR: Multiple linear regression; NTD: Neglected Tropical Diseases; Plt: Platelet; RBC: Red blood cell; RDW-CV: Red cell distribution width-coefficient of variation; SAC: School-aged children; SD: Standard deviation; UGS: Urogenital schistosomiasis; WA: Weight-for-age; WH: Weight-for height; WBC: White blood cell; WHO: World Health Organisation

\section{Supplementary Information}

The online version contains supplementary material available at https://doi. org/10.1186/s12879-021-06201-9.

Additional file 1. Multiple linear regression analysis examining the influence of independent variables on some haematological parameters. Although not statistically significant UGS had a negative influence on $\mathrm{Hb}$, Hct, WBC, RBC and lymphocyte counts, MCV, MCH and MCHC.

\section{Acknowledgements}

The authors are thankful to the parents/guardians, teachers as well as the children who participated in the study. We acknowledge the support of IIESRF (Institute of International Education-Scholar Rescue Fund) and Master of Public Health programme, College of Veterinary Medicine, Cornell University, Ithaca, New York in providing the fellowship and appropriate academic resources for the drafting of this manuscript.

\section{Authors' contributions}

IUNS was involved conceptualization, data curation, supervision, writing of original draft, review and editing of the manuscript; OVO, CBE TRN participated in methodology, laboratory analysis; LF participated in editing and revision of the manuscript; OSMB, HKK, TNA contributed in supervision, editing and revision of the manuscript. All authors read and approved the final manuscript.

\section{Funding}

The authors received no specific funding for the study. However, the work was supported by the special fund for research and modernization given to authors by the Government of Cameroon who had no role in study design, data collection and analysis, decision to publish, or preparation of the manuscript.

Availability of data and materials

All datasets generated and analysed in the current study are presented in the paper and supporting information file.

\section{Declarations}

Ethics approval and consent to participate

The study protocol was reviewed and approved by the Institutional Ethical Review Board hosted by the Faculty of Health Sciences, University of Buea following administrative authorisation from the Regional Delegation of Public Health and Basic Education. The ethical approval reference for the study is 2014/243/UB/FHS/IRB. The study was conducted in accordance with the World Medical Association (WMA) principles as stated in the Declaration of Helsinki. The population was sensitized in their various communities at the beginning of the study. Written informed consent was obtained from all parents/caregivers whose child/children participated in the study after explaining the purpose and benefits of their participation. Participation was totally voluntary, and a participant could decide to halt their participation in the study at any time without any penalty. Participants who had malaria and or helminths were given first line treatment as recommended by the national treatment guideline policy for uncomplicated malaria and helminths.

Consent for publication

Not applicable.

Competing interests

The authors declare that they have no competing interests. 


\section{Author details}

'Department of Zoology and Animal Physiology, University of Buea, Buea, Cameroon. ${ }^{2}$ Department of Microbiology and Immunology, College of Veterinary Medicine, Cornell University, Ithaca, New York, USA. ${ }^{3}$ Department of Population Medicine and Diagnostic Services, College of Veterinary Medicine, Cornell University, Ithaca, New York, USA. ${ }^{4}$ Department of Medical Laboratory Sciences, Faculty of Health Sciences, University of Buea, Buea, Cameroon. ${ }^{5}$ Department of Medical Laboratory Science, Faculty of Health Sciences, University of Bamenda, Bambili, Cameroon. ${ }^{6}$ Department of Microbiology and Parasitology, University of Buea, Buea, Cameroon.

\section{Received: 18 November 2020 Accepted: 17 May 2021} Published online: 25 May 2021

\section{References}

1. Hotez PJ, Alvarado M, Basa MG, Bolliger I, Bourne R, Michel Boussinesq M, et al. The global burden of disease study 2010: interpretation and implications for the neglected tropical diseases. PLoS Negl Trop Dis. 2014; 8(7):e2865. https://doi.org/10.1371/journal.pntd.0002865.

2. Grimes JET, Croll D, Harrison WE, Utzinger J, Freeman MC, Templeton MR. The relationship between water, sanitation and schistosomiasis: a systematic review and meta-analysis. PLoS Negl Trop Dis. 2014;8(12):e3296. https://doi. org/10.1371/journal.pntd.0003296.

3. Yang D, He Y, Wu B, Deng Y, Li M, Yang Q, et al. Drinking water and sanitation conditions are associated with the risk of malaria among children under five years old in sub-Saharan Africa: a logistic regression model analysis of national survey data. J Adv Res. 2020;21:1-13. https://doi.org/10.1 016/j.jare.2019.09.001.

4. Nankabirwa J, Brooker SJ, Clarke SE, Fernando D, Gitonga CW, Schellenberg $D$, et al. Malaria in school-age children in Africa: an increasingly important challenge. Trop Med Int HIth. 2014;19(11):1294-309. https://doi.org/10.1111/ tmi.12374.

5. Martins AC, Araújo FM, Braga CB, Guimarães MGS, Nogueira R, Arruda RA, et al. Clustering symptoms of non-severe malaria in semi-immune Amazonian patients. PeerJ. 2015;3:e1325. https://doi.org/10.7717/peerj.1325.

6. Walldorf JA, Cohee LM, Coalson JE, Bauleni A, Nkanaunena K, Kapito-Tembo $A$, et al. School-age children are a reservoir of malaria infection in Malawi. PLoS One. 2015;10(7):e0134061. https://doi.org/10.1371/journal.pone.0134 061.

7. Ebai CB, Kimbi HK, Sumbele IUN, Yunga JE, Lehman LG. Epidemiology of Plasmodium falciparum malaria in the Ikata-Likoko area of Mount Cameroon: a cross sectional study. IJTDH. 2016;16(4):1-12. https://doi.org/10.9734/ IJTDH/2016/25890.

8. Mwandagalirwa KM, Levitz L, Thwai KL, Parr JB, Goel V, Janko M, et al. Individual and household characteristics of persons with Plasmodium falciparum malaria in sites with varying endemicities in Kinshasa Province, Democratic Republic of the Congo. Malar J. 2017;16(1):456.

9. Minsante. Xlième Journée mondiale de lutte contre le paludisme "prêt à vaincre le paludisme" Nous sommes la génération qui peut éliminer le paludisme. Dossier de Presse. Minsante. 2018:1-20. (French).

10. Maru DS. Prevalence of intestinal parasitic infections and associated risk factors among school children in Adigrat town, northern Ethiopia. Int J Emerg Trends Sci Technol. 2015;4(1):4943-8.

11. Hotez PJ, Aksoy S, Brindley PJ, Kamhawi S. What constitutes a neglected tropical disease? PLoS Negl Trop Dis. 2020;14(1):e0008001. https://doi.org/1 0.1371/journal.pntd.0008001.

12. WHO. Schistosomiasis key facts. 2020. https://www.who.int/news-room/fa ctsheets/detail/schistosomiasis. Accessed 16 Nov 2020.

13. Anguh $E$, Ako $S$, Numfor $E$, Josiah ZB, Ndassi V. Presence of an unmapped focus for urogenital schistosomiasis in the Tiko Health District in Cameroon: implications for control. IJTDH. 2018;32(2):1-8. https://doi.org/10.9734/ IJTDH/2018/43575.

14. Ebai CB, Kimbi HK, Sumbele IUN, Yunga JE, Lehman LG. Prevalence and risk factors of urinary schistosomiasis in the Ikata-Likoko area of Southwest Cameroon. IJTDH. 2016;17(2):1-10. https://doi.org/10.9734/IJTDH/2016/2 6669.

15. Nono JK, Kamdem SD, Netongo PM, Dabee S, Schomaker M, Oumarou A, et al. Schistosomiasis burden and its association with lower measles vaccine responses in school children from rural Cameroon. Front Immunol. 2018;9:2295.
16. Ntonifor HN, Green AE, Bopda MOS, Tabot JT. Epidemiology of urinary schistosomiasis and soil transmitted helminthiasis in a recently established focus behind Mount Cameroon. Int J Curr Microbiol App Sci. 2015;4(3): 1056-66.

17. Tchuem Tchuente LA, Dongmo NC, Ngassam P, Kenfack CM, Gipwe NF, Dankoni E, et al. Mapping of schistosomiasis and soil-transmitted helminthiasis in the regions of Littoral, north-west, South and South-West Cameroon and recommendations for treatment. BMC Infect Dis. 2013;13: 602.

18. Tchuem Tchuente LA, Momo SC, Stothard JR, Rollinson D. Efficacy of praziquantel and reinfection patterns in single and mixed infection foci for intestinal and urogenital schistosomiasis in Cameroon. Acta Trop. 2013; 128(2):275-83. https://doi.org/10.1016/j.actatropica.2013.06.007.

19. Ebai CB, Kimbi HK, Sumbele IUN, Yunga JE, Lehman LG. Efficacy and safety of praziquantel against Schistosoma haematobium in the Ikata-Likoko area of Southwest Cameroon. Trop Med Health. 2017;45(1):30. https://doi.org/1 0.1186/s41182-017-0071-8.

20. Bryan FJ. The design and analysis of research studies. UK: University of Otago, Cambridge University Press; 1992.

21. WHO. AnthroPlus for personal computers manual: Software for assessing growth of the world's children and adolescents. Geneva: World Health Organization; 2009. http://www.int/growthref/tools/who_anthr oplus_ma nual.pdf. Accessed 16 Nov 2020

22. Kateera F, Ingabire CM, Hakizimana E, Kalinda P, Mens PF, Grobusch MP, et al. Malaria, anaemia and under-nutrition: three frequently coexisting conditions among preschool children in rural Rwanda. Malar J. 2015;14(1): 440. https://doi.org/10.1186/s12936-015-0973-z.

23. Cheesbrough M. District laboratory practice in tropical countries: Part1\&2: Cambridge university press; 2014.

24. Allen S, Ennett S, Riley E, Rowe P, Jakobsen P, Donnell A, et al. Morbidity from malaria and immune responses to defined Plasmodium falciparum antigens in children with sickle cell trait in the Gambia. Trans R Soc Trop Med Hyg. 1992;86(5):494-8. https://doi.org/10.1016/0035-9203(92)90083-O.

25. WHO. Iron deficiency anaemia: assessment, prevention and control, a quide for programme managers. Geneva: World Health Organization Publication; 2001. http://www.who.int/nutrition/publications/micronutrients/anaemia iron_deficiency/WHO_NHD_01.3/en/index.html. Accessed 16 Nov 2020

26. Tohon ZB, Mainassara HB, Garba A, Mahamane AE, Bosqué-Oliva E, Ibrahim $M L$, et al. Controlling schistosomiasis: significant decrease of anaemia prevalence one year after a single dose of praziquantel in Nigerien schoolchildren. PLoS Negl Trop Dis. 2008;2(5):e241. https://doi.org/10.1371/ journal.pntd.0000241.

27. Nkengazong L, Njiokou F, Asonganyi T. Two years impact of single praziquantel treatment on urinary schistosomiasis in the Barombi Kotto focus, south West Cameroon. J Parasitol Vector Biol. 2013;5(6):83-9.

28. Benichou J. A review of adjusted estimators of attributable risk. Stat Methods Med Res. 2001;10(3):195-216. https://doi.org/10.1177/0962280201 01000303.

29. Anchang-Kimbi JK, Elad DM, Sotoing GT, Achidi EA. Coinfection with Schistosoma haematobium and Plasmodium falciparum and anaemia severity among pregnant women in Munyenge, Mount Cameroon Area: a cross-sectional study. J Parasitol Res. 2017;2017:6173465.

30. Sumbele IUN, Nkain AJ, Ning TR, Anchang-Kimbi JK, Kimbi HK. Influence of malaria, soil-transmitted helminths and malnutrition on haemoglobin level among school aged children in Muyuka, Southwest Cameroon: a crosssectional study on outcomes. PLoS One. 2020;15(3):e0230882. https://doi. org/10.1371/journal.pone.0230882.

31. Leonard KTD, Khan PV, Gustave LL, Tiburce G. Some haematological parameters among urinary schistosomiasis malaria coinfected children in suburb of Malentouen Health District, West Region Cameroon. IJTDH. 2020; 41(7):34-44.

32. Kinung'hi SM, Mazigo HD, Dunne DW, Kepha S, Kaatano G, Kishamawe C, et al. Coinfection of intestinal schistosomiasis and malaria and association with haemoglobin levels and nutritional status in school children in Mara region, Northwestern Tanzania: a cross-sectional exploratory study. BMC Res Notes. 2017;10(1):583.

33. Campbell SJ, Stothard JR, O'Halloran F, Sankey D, Durant T, Ombede DE, et al. Urogenital schistosomiasis and soil-transmitted helminthiasis (STH) in Cameroon: an epidemiological update at Barombi Mbo and Barombi Kotto crater lakes assessing prospects for intensified control interventions. Infect Dis Poverty. 2017;6(1):49. https://doi.org/10.1186/s40249-017-0264-8. 
34. Mewabo AP, Moyou RS, Kouemeni LE, Ngogang JY, Kaptue L, Tambo E. Assessing the prevalence of urogenital schistosomaisis and transmission risk factors amongst school-aged children around Mape dam ecological suburbs in Malantouen district, Cameroon. Infect Dis Poverty. 2017;6(1):40. https://doi.org/10.1186/s40249-017-0257-7.

35. Noriodea RM, Idowua ET, Otubanjoa OA, Mafeb MA. Urinary schistosomiasis in school aged children of two rural endemic communities in Edo state. Nigeria J Infect Public Health. 2018;11(3):384-8. https://doi.org/10.1016/j. jiph.2017.09.012.

36. Njunda AL, Ndzi EN, Assob JCN, Kamga HLF, Kwenti ET. Prevalence and factors associated with urogenital schistosomiasis among primary school children in barrage, Magba sub-division of Cameroon. BMC Public Health. 2017;17(1):618. https://doi.org/10.1186/s12889-017-4539-6

37. Abdulkareem BO, Habeeb KO, Kazeem A, Adam AO, Uade Samuel UU. Urogenital schistosomiasis among schoolchildren and the associated risk factors in selected rural communities of Kwara State, Nigeria. J Trop Med. 2018:2018:6913918 Article ID 6913918.

38. Dejon-Agobe JC, Zinsou JF, Honkpehedji YJ, Ateba-Ngoa U, Edoa J-R, Adegbite BR, et al. Schistosoma haematobium effects on Plasmodium falciparum infection modified by soil-transmitted helminths in school-age children living in rural areas of Gabon. PLoS Negl Trop Dis. 2018;12(8): e0006663.

39. Nyarko R, Torpey K, Ankomah A. Schistosoma haematobium, Plasmodium falciparum infection and anaemia in children in Accra, Ghana. Trop Dis Travel Med Vaccines. 2018;4(1):3. https://doi.org/10.1186/s40794-018-0063-7.

40. Oladele VS, Awobode HO, Anumudu Cl. Subtle morbidities associated with malaria co-infection with schistosomiasis among children in south-West Nigeria. Afr J Med Med Sci. 2014;43(Suppl):125-35.

41. Antonio-Nkondjio C, Ndo C, Njiokou F, Bigoga JD, Awono-Ambene P, Etang $J$, et al. Review of malaria situation in Cameroon: technical viewpoint on challenges and prospects for disease elimination. Parasit Vectors. 2019;12(1): 501. https://doi.org/10.1186/s13071-019-3753-8.

42. Ayeh-Kumi PF, Addo-Osafo K, Attah SK, Tetteh-uarcoo PB, Obeng-Nkrumah $\mathrm{N}$, Awuah-Mensah G, et al. Malaria, helminths and malnutrition: a crosssectional survey of school children in the south-Tongu district of Ghana. BMC Res Notes. 2016;9(1):242. https://doi.org/10.1186/s13104-016-2025-3.

43. Frigerio S, Macario M, lacovone G, Dussey-Comlavi KJ, Narcisi P, Ndiaye AT, et al. Schistosoma haematobium infection, health and nutritional status in school-age children in a rural setting in Northern Senegal. Minerva Pediatr. 2016;68(4):282-7.

44. Tabi ESB, Cumber SN, Juma KO, Ngoh EA, Akum EA, Eyong EM. A crosssectional survey on the prevalence of anaemia and malnutrition in primary school children in the Tiko health district, Cameroon. Pan Afri Med J. 2019; 32:111.

45. Wamani H, Åstrøm AN, Peterson S, Tumwine JK, Tylleskär T. Boys are more stunted than girls in sub-Saharan Africa: a meta-analysis of 16 demographic and health surveys. BMC Pediatr. 2007;7(1):17. https://doi.org/10.1186/14 71-2431-7-17.

46. Al-Mansoob MAK, Masood MSA. The relationship between stunting and some demographic and socioeconomic factors among Yemeni children and adolescents. Adv Public Health. 2018;1:5619178.

47. Olney DK, Kariger PK, Stoltzfus RJ, Khalfan SS, Ali NS, Tielsch JM, et al. Development of nutritionally at-risk young children is predicted by malaria, anemia, and stunting in Pemba, Zanzibar ${ }^{1-3}$. J Nutr. 2009;139(4):763-72. https://doi.org/10.3945/jn.107.086231.

48. Gari T, Loha E, Deressa W, Solomon T, Lindtjørn B. Malaria increased the risk of stunting and wasting among young children in Ethiopia: results of a cohort study. PLoS One. 2018;13(1):e0190983. https://doi.org/10.1371/journa I.pone.0190983.

49. Kimbi HK, Sumbele IU, Nweboh M, Anchang-Kimbi JK, Lum E, Nana Y, et al. Malaria and haematologic parameters of pupils at different altitudes along the slope of Mount Cameroon: a cross-sectional study. Malar J. 2013;12(1): 193. https://doi.org/10.1186/1475-2875-12-193.

50. Kotepui M, Phunphuech B, Phiwklam N, Chupeerach C, Duangmano S Effect of malarial infection on haematological parameters in population near Thailand-Myanmar border. Malar J. 2014;13(1):218. https://doi.org/10.11 86/1475-2875-13-218.

51. Valice EM, Wiegand RE, Mwinzi PNM, Karanja DMS, Williamson JM, Ochola E, et al. Relative contribution of schistosomiasis and malaria to anemia in western Kenya. Am J Trop Med Hyg. 2018;99(3):713-5. https://doi.org/10.42 69/ajtmh.18-0069.
52. Deribew K, Tekeste Z, Petros B, Huat LB. Urinary schistosomiasis and malaria associated anemia in Ethiopia. Asian Pac J Trop Biomed. 2013;3(4):307-10. https://doi.org/10.1016/S2221-1691(13)60068-4.

53. Kitua AY, Smith TA, Alonso PL, Urassa H, Masanja H, Kimario J, et al. The role of low-level Plasmodium falciparum parasitaemia in anaemia among infants living in an area of intense and perennial transmission. Tropical Med Int Health. 1997;2(4):325-33. https://doi.org/10.1111/j.1365-3156.1997.tb00147.x.

54. Menendez C, Fleming AF, Alonso PL. Malaria-related anaemia. Parasitol Today. 2000;16(11):469-76. https://doi.org/10.1016/S0169-4758(00)01774-9.

55. Friedman JF, Kanzaria HK, McGarveyac ST. Human schistosomiasis and anemia: the relationship and potential mechanisms. Trends Parasitol. 2005; 21(8):386-92. https://doi.org/10.1016/j.pt.2005.06.006.

56. Kotepui M, Piwkham D, PhunPhuech B, Phiwklam N, Chupeerach C, Duangmano S. Effects of malaria parasite density on blood cell parameters. PLoS One. 2015;10(3):e0121057. https://doi.org/10.1371/journal.pone.0121 057.

57. Haldar K, Mohandas N. Malaria, erythrocytic infection, and anemia. Hematology Am Soc Hematol Educ Program. 2009;2009(1):87-93. https:// doi.org/10.1182/asheducation-2009.1.87.

58. Suwanarusk R, Cooke BM, Dondorp AM, Silamut K, Sattabongkot J, White $\mathrm{NJ}$, et al. The deformability of red blood cells parasitized by Plasmodium falciparum and P. vivax. J Infect Dis. 2004;189:190-4.

59. Behera S, Bulliyya G. Magnitude of anemia and hematological predictors among children under 12 years in Odisha, India. Anemia. 2016;2016: 1729147.

60. Bhoite $R$, lyer U. Magnitude of malnutrition and iron deficiency anemia among rural school children: an appraisal. Asian J Experimental Biol Sc. 2011;2(2):354-61.

61. Sumbele IUN, Nkuo-Akenji T, Samje M, Ndzeidze T, Ngwa EM, Titanji VPK. Haematological changes and recovery associated with treated and untreated Plasmodium falciparum infection in children in the Mount Cameroon region. J Clin Med Res. 2010;2(9):143-51.

62. Sumbele IUN, Sama SO, Kimbi HK, Taiwe GS. Malaria, moderate to severe anaemia, and malarial anaemia in children at presentation to hospital in the Mount Cameroon area: a cross-sectional study. Anemia. 2016;2016:5725634.

63. Petro TM, Schwartz KM, Chen SSA. Production of IL2 and IL3 in syngeneic mixed lymphocyte reactions of BALB/C mice are elevated during a period of moderate dietary protein deficiency. Immunol Investig. 1994;23(2):143-52. https://doi.org/10.3109/08820139409087795.

64. Otoni A, Antunes CMF, Tavares FF, Araújo DHQ, Pereira TA, Queiroz LC, et al. Thrombocytopenia as a marker of liver steatosis in a low-endemic area for Schistosomiasis mansoni. Rev Assoc Med Bras. 1992;63(6):532-7.

65. Angchaisuksiri P. Coagulopathy in malaria. Thromb Res. 2014;133(1):5-9. https://doi.org/10.1016/j.thromres.2013.09.030.

66. Gupta NK, Bansal SB, Jain UC, Sahare K. Study of thrombocytopenia in patients of malaria. Trop Parasitol. 2013;3(1):58-61. https://doi.org/10.41 03/2229-5070.113914.

67. Sumbele IU, Ning TR, Bopda OS, Nkuo-Akenji T. Variation in malariometric and red cell indices in children in the Mount Cameroon area following enhanced malaria control measures: evidence from a repeated crosssectional study. Malar J. 2014;13(1):334. https://doi.org/10.1186/1475-2 875-13-334.

\section{Publisher's Note}

Springer Nature remains neutral with regard to jurisdictional claims in published maps and institutional affiliations.

Ready to submit your research? Choose BMC and benefit from:

- fast, convenient online submission

- thorough peer review by experienced researchers in your field

- rapid publication on acceptance

- support for research data, including large and complex data types

- gold Open Access which fosters wider collaboration and increased citations

- maximum visibility for your research: over $100 \mathrm{M}$ website views per year

At $\mathrm{BMC}$, research is always in progress.

Learn more biomedcentral.com/submissions 